\title{
Elaboração e validação de um jogo didático sobre saúde bucal
}

\author{
Elaboration and validation of a didactic game on oral health \\ Elaboración y validación de un juego didático sobre salud bucal
}

Recebido: 06/12/2021 | Revisado: 15/12/2021 | Aceito: 21/12/2021 | Publicado: 03/01/2022

Paulla Valéria de Souza Meneses

ORCID: https://orcid.org/0000-0001-6749-9377

Universidade Estadual de Ciências da Saúde de Alagoas, Brasil

E-mail: paullavaleria@ hotmail.com

Érica Paula Barbosa

ORCID: https://orcid.org/0000-0002-8280-4699

Universidade Estadual de Ciências da Saúde de Alagoas, Brasil

E-mail: erica.barbosa@academico.uncisal.edu.br

Cinthya Rafaella Magalhães da Nóbrega Novaes

ORCID: https://orcid.org/0000-0003-4795-6328

Universidade Estadual de Ciências da Saúde de Alagoas, Brasil E-mail: rafamn20@yahoo.com.br

Ana Renata Lima Leandro

ORCID: https://orcid.org/0000-0003-2707-0730

Universidade Estadual de Ciências da Saúde de Alagoas, Brasil E-mail: releandro@gmail.com

Flávia Accioly Canuto Wanderley

ORCID: https://orcid.org/0000-0003-0775-9119

Universidade Estadual de Ciências da Saúde de Alagoas, Brasil

E-mail: flavia.accioly@uncisal.edu.br

Carmen Silvia Motta Bandini

ORCID: https://orcid.org/0000-0002-4731-5785

Universidade Estadual de Ciências da Saúde de Alagoas, Brasil

E-mail: carmen.bandini@uncisal.edu.br

\begin{abstract}
Resumo
O presente estudo descreve as etapas de estruturação e validação de um jogo didático, com o propósito de promover o aprendizado sobre saúde bucal em escolares, estimular a prática da escovação dentária e fornecer orientações sobre alimentos cariogênicos e não cariogênicos. O desenvolvimento do jogo foi baseado no método CTM3 e na metodologia da aprendizagem sem erros. Trata-se de um jogo, do tipo tabuleiro, em formato de boca, com 32 casas que assumiram o formato de dentes. Para a validação do jogo, dois instrumentos foram preenchidos por especialistas, com título de doutor nas áreas de educação ou saúde, e experiência na produção de materiais educativos e didáticos. Os especialistas validaram o jogo e sugeriram algumas melhorias em determinadas instruções aos alunos, tais como: especificar melhor os comportamentos que deveriam ser emitidos pelas crianças e adequar certas representações visuais. As adequações sugeridas foram realizadas e o jogo, posteriormente, passou por validação de banca de defesa de um Programa de Mestrado Profissional em uma Instituição de Ensino Superior de Alagoas. Assim, o jogo foi estruturado e validado para ajudar os professores a trabalharem a temática da saúde bucal no ambiente escolar. Por se tratar de um processo divertido e atrativo espera-se despertar nas crianças que farão uso do jogo, a vontade de realizar sua higiene oral e, nos professores o interesse em introduzir a temática saúde bucal nas suas atividades didáticas.
\end{abstract}

Palavras-chave: Saúde bucal; Jogos; Produtos educacionais; Educação em saúde; Ensino.

\begin{abstract}
This study describes the stages of structuring and validating a didactic game, with the purpose of promoting learning about oral health in schoolchildren, encouraging the practice of toothbrushing and providing guidance on cariogenic and non-cariogenic foods. The game's development was based on the CTM3 method and the error-free learning methodology. It is a board-type game, in the shape of a mouth, with 32 spaces that assumed the shape of teeth. To validate the game, two instruments were filled out by specialists with a $\mathrm{PhD}$ in the areas of education or health, and experience in the production of educational and didactic materials. Experts validated the game and suggested some improvements in certain instructions to students, such as: better specifying the behaviors that should be emitted by children and adapting certain visual representations. The suggested adjustments were made and the game was subsequently validated by the defense panel of a Professional Master's Program at a Higher Education Institution in Alagoas. Thus, the game was structured and validated to help teachers work on the topic of oral health in the school environment. As this is a fun and attractive process, it is expected to awaken in children who will use the game, the
\end{abstract}


desire to perform their oral hygiene and, in teachers, an interest in introducing the topic of oral health in their teaching activities.

Keywords: Oral health; Games; Educational products; Health education; Teaching.

\section{Resumen}

Este estudio describe las etapas de estructuración y validación de un juego didáctico, con el propósito de promover el aprendizaje sobre la salud bucal en escolares, incentivar la práctica del cepillado de dientes y orientar sobre alimentos cariogénicos y no cariogénicos. El desarrollo del juego se basó en el método CTM3 y la metodología de aprendizaje sin errores. Es un juego de mesa, en forma de boca, con 32 espacios que asumían la forma de dientes. Para validar el juego, se completaron dos instrumentos por especialistas con doctorado en las áreas de educación o salud, y experiencia en la producción de materiales educativos y didácticos. Los expertos validaron el juego y sugirieron algunas mejoras en ciertas instrucciones a los estudiantes, como: especificar mejor los comportamientos que deben emitir los niños y adaptar ciertas representaciones visuales. Se realizaron los ajustes sugeridos y posteriormente el juego fue validado por el panel de defensa de un Programa de Maestría Profesional en una Institución de Educación Superior en Alagoas. Así, el juego fue estructurado y validado para ayudar a los profesores a trabajar el tema de la salud bucal en el ámbito escolar. Al tratarse de un proceso divertido y atractivo, se espera despertar en los niños que utilizarán el juego, el deseo de realizar su higiene bucal y, en los docentes, el interés por introducir el tema de la salud bucal en sus actividades docentes.

Palabras clave: Salud bucal; Juegos; Productos educativos; Educación para la salud; Enseñando.

\section{Introdução}

A Educação em Saúde Bucal implica no conhecimento e na conscientização das pessoas, aliada ao desenvolvimento das habilidades necessárias para alcançá-la. É, portanto, focada em oportunidades de aprendizagem e pode ser desenvolvida em diversos espaços sociais, grupos populacionais e com diferentes atividades (Mallmann et al., 2015).

Em Odontologia, a Educação em Saúde também tem grande importância para a promoção da saúde bucal, principalmente para o público infantil (Cota \& Costa, 2017). A ideia de introduzi-la em forma de metodologias ativas, como no caso das atividades lúdicas, apresenta-se como ferramenta de extrema relevância na transmissão de conhecimento sobre temas pertinentes (Mouta et al., 2020).

Dentre a diversidade de programas e estratégias utilizadas para promover a saúde bucal em crianças, a ludicidade para esta população tem se mostrado como uma das alternativas promissoras, mas, ainda pouco explorada. Observa-se, também, que, mesmo quando elementos lúdicos são utilizados, ocorrem de forma pontual. As atividades lúdicas funcionam atraindo a atenção e gerando a motivação da criança no processo de aprendizagem e estimulam, ainda, a mudança ou adoção de comportamentos que possam melhorar a sua qualidade de vida (Costa et al., 2017).

A aplicação dessas atividades lúdicas, com fins de trabalhar comportamentos em saúde para a população infantil, representa a incorporação de um conhecimento simples, mas que corresponde a um grande processo profilático contra grande parte das doenças que acometem esse público, tais como: cárie dentária, pediculose e síndromes diarreicas em geral (Castro et al., 2018; Gonçalves et al., 2020).

Para manter a saúde bucal, especificamente, a escovação dos dentes é considerada a prática mais eficaz. Este hábito, assim como todos os outros hábitos de higiene, é adquirido durante o processo de socialização da criança. Quando ensinados no início da infância, naturalmente são incorporados em sua rotina diária. Contudo, o uso exclusivo de instruções verbais dadas durante a infância tem se mostrado pouco promissor para mudança de comportamento desses indivíduos, uma vez que sua compreensão gramatical é muito pequena e permanece assim por alguns anos (Adistia et al., 2020).

Percebe-se então, que a escolha de um recurso ou da associação de diferentes estratégias lúdicas, direcionadas ao público infantil, deve ser feita de forma racional, por meio de ferramentas que tornem o processo de aprendizagem dinâmico e de fácil compreensão, considerando não apenas as preferências e habilidades dos profissionais, mas sobretudo, a adequação dos temas, das regras e das ações da atividade à idade a ao nível cognitivo e motor de desenvolvimento da criança (Cota \& Costa, 2017). 
Santos et al. (2019) acresentam que, ao escolher um produto educacional para ser empregado em atividades lúdicas, precisa-se levar em conta, além dos aspectos já mencionados e o conhecimento técnico do que se pretende abordar, os aspectos sistêmicos que devem estar incluidos na elaboração desse produto.

A brincadeira, segundo os educadores, é uma ferramenta valiosa para a aprendizagem por produzir uma motivação intrínseca. Por isso, ambientes divertidos, que facilitem a promoção de atividades com uso de recursos interessantes, são desejáveis (Venâncio et al., 2011). Dentre os recursos que podem ser utilizados na brincadeira estão os jogos, que já fazem parte da história do ser humano, desde a sua primeira infância, evoluindo no seu simbolismo e complexidade. O brincar é essencial ao desenvolvimento cognitivo da criança, bem como faz parte do contexto do processo de construção do conhecimento. (Prado, 2018).

Nessa perspectiva de ferramenta pedagógica na área da saúde, os jogos vêm sendo utilizados para fomentar a prática de exercícios físicos (Novaes, 2020); promover a saúde cardiovascular de adolescentes (Lima et al., 2020) e da criança (Costa, 2020), como estratégia para promoção de saúde mental de acompanhantes de pacientes hospitalizados (Oliveira et al., 2018), para prevenir a obesidade em crianças e adolescentes (Brito et al., 2020), na prevenção de acidentes domésticos na infância (Araújo et al., 2021) entre outras aplicabilidades, no contexto da educação em saúde e no processo do cuidado, buscando o empoderamento potencial em autocuidado do indivíduos.

Kishimoto (1994) considera os jogos como uma atividade lúdica, que possui duas funções: a lúdica e a educativa, e estas devem estar balanceadas, não podendo uma predominar sobre a outra. Se deixarmos o lúdico predominar, teremos apenas um jogo e se a função educativa prevalecer, teremos apenas um material didático.

Ainda de acordo com Kishimoto (1996), os jogos não podem ser considerados o fim da aplicação de um conteúdo, mas sim um instrumento que favorece a construção daquele conteúdo didático, por meio da relação do lúdico com as informações. Com frequência, o jogo empregado na escola aparece como um recurso para a realização de atividades educativas sendo um elemento fundamental ao desenvolvimento do aluno, assim, qualquer jogo empregado pela escola, apresenta o caráter educativo e pode também receber a denominação geral de jogo educativo, mas, o que torna o jogo educativo é a intenção explicita de provocar a aprendizagem. (Kishimoto, 2004).

No ambiente escolar, é muito importante ressaltar que para obter êxito com a utilização dos jogos, precisa-se da mediação dos professores (Ferri \& Soares, 2015). O desafio deles é fazer com que o conhecimento necessário para ser adquirido pelo aprendiz (aluno), passe da memória de curto prazo para a de longo prazo, ou memória permanente, e este processo precisa acontecer rapidamente (Prado, 2018).

Em relação à saúde bucal, os jogos vêm sendo desenvolvidos para fomentar e disseminar boas práticas de saúde bucal, envolvendo assuntos como: cárie, alimentação saudável, doença periodontal, higienização correta da cavidade oral e câncer bucal, favorecendo a construção de novos conhecimentos, hábitos e cuidados (Fadel et al., 2018; Casseb et al., 2020). Como exemplos, Santos et al. (2020) apresentam jogos de saúde bucal nos formatos de quebra-cabeça, tabuleiro, como o Dentorama e jogo on line, tipo o LittleBoo - Meu dentinho virtual.

Outros exemplos de utilização de elementos lúdicos em saúde bucal são os estudos de Corrêa et al. (2019), que desenvolveram um programa de prevenção e educação em saúde bucal, com crianças de 2 a 5 anos, utilizando entre outros recursos, os jogos. O programa faz parte do Projeto de extensão "Atenção Integral em Saúde Bucal” na creche Sorena, há 17 anos, e têm refletido na melhora das condições de saúde bucal das crianças. Os autores observaram uma melhor aceitação ao tratamento odontológico, com um comportamento mais tranquilo e menos traumático das crianças durante o atendimento odontológico, impactando diretamente na diminuição da incidência de cárie e doença periodontal desses estudantes.

Pode-se citar também o estudo de Oliveira, Santos e Santos (2002), que avaliaram o aprendizado em 60 crianças de 8 (oito) anos, usando jogos educativos como meio auxiliar na mudança de hábitos de higiene bucal. As crianças expostas aos 
jogos apresentaram maior efetividade na qualidade da higiene bucal que as que apenas tiveram instruções de higiene oral de maneira convencional.

Aguiar et al. (2018) realizaram um estudo com 29 estudantes, de 11 e 17 anos, no qual elaboraram um jogo de cartas denominado Jogo SB (Saúde Bucal). O jogo era composto por 69 cartas e apresentava uma doença, uma causa ou consequência e uma prevenção, cujo objetivo final era descobrir o diagnóstico confidencial. As cartas podem ser jogadas por grupos de 2 a 4 pessoas e os jogadores devem seguir as regras descritas. Os resultados dão conta de que houve um aumento no número de respostas corretas no pós jogo e que a participação e o interesse dos jogadores foram satisfatórios na ampliação de conhecimentos, permitindo a esses adolescentes empoderamento em autocuidado com a saúde bucal.

Ações de promoção à saúde também foram desenvolvidas por Oliveira et al. (2016), com alunos de 5 a 12 anos, abordando vários temas de saúde bucal, utilizando personagens heroicos, por meio de palestras, teatro e jogos recreativos. Os autores avaliaram dieta e escovação supervisionada, fizeram evidenciação de biofilme dental e aferiram o índice de higiene oral simplificado (IHOS), que serve para avaliar a qualidade da escovação e presença de biofilme nos dentes. Ao final da intervenção observaram uma melhora no grau de higiene oral dessas crianças com queda no IHOS.

Garcia et al. (2009) contaram com 120 crianças do $2^{\circ}$ ano do ensino fundamental ( 8 a 10 anos) para aplicação de um método lúdico, o gibi, com diferentes abordagens e avaliaram em dois períodos, antes e depois da intervenção os níveis de higiene oral dos escolares. Para isso, dividiram as crianças em quatro grupos, que passaram por intervenções diferentes utilizando o gibi: G1 - controle, G2 - leitura do gibi, G3 - discussão sobre a história do gibi e G4 -reescrita da história. Como resultado da intervenção, verificou-se uma diminuição no índice de placa, comparada às duas medições. Isso reflete a realização de uma melhor higiene oral, com uma diminuição mais significante entre os grupos discussão e reescrita da história.

O jogo eletrônico educativo chamado Dentinho foi desenvolvido por Figueiredo, Garcia, Barone, Oliveira e Lurmmez (2015) que testaram com 45 alunos de ensino fundamental. O jogo apresenta várias fases, nas quais a higiene oral e alimentação saudável são os recursos para passar de fase e ao final o jogador conquista a saúde bucal. Todos os alunos, após o jogo, afirmaram sentirem-se motivados a cuidar de seus dentes. Os autores avaliaram a intervenção como bastante satisfatória, constatando a obtenção de novos conhecimentos em 96,6\% dos estudantes que 69,9\% aumentaram o interesse pelo assunto escovação dentária.

Ao se tratar sobre jogo e ludicidade em seu sentido mais amplo, um tipo de jogo se destaca: os jogos de tabuleiro. Eles promovem a interação direta entre um grupo de jogadores, sem exigir meio eletrônicos como mediadores dessa interação (Kishimoto, 2004).

Além disso, de acordo com Casseb et al. (2020) os jogos de tabuleiro se tornam uma importante ferramenta para educação de saúde bucal e favorecem a ação do professor como facilitador do processo de criação do ambiente lúdico (Kishimoto, 2004). Esse tipo de jogo, também, pode explorar outros conteúdos, adapta-se a diversas situações, mudando-se as gravuras e não esquecendo de relacionar as questões com o contexto dos alunos, sendo esse o motivo maior do sucesso dos jogos, pois eles se sentem familiarizados com o assunto e conseguem responder às questões. Além disso, esses jogos, favorecem o ensino mais espontâneo, contextualizado, motivacional e divertido, mostrando que é possível aprender brincando (Mouta et al., 2020).

Para Campestrini et al. (2019), aprender a ensinar, elaborar atividades condizentes com a fase de desenvolvimento da criança e expandir sua criatividade, são desafios presentes na rotina de quem pratica ações educativas em ambiente escolar. Contudo, os autores sugerem que sejam planejadas atividades em que as crianças possam se engajar com a mínima probabilidade de serem expostas a constantes fracassos, pois, atividades que as exponham a situações de tentativa e erro, por exemplo, nas quais o aprendiz se expõe, sem qualquer guiamento para o seu comportamento, fazem com que ele tenha a oportunidade de errar muitas vezes até encontrar a resposta correta, favorecendo o aparecimento de respostas emocionais 
negativas e comportamentos de fuga ou esquiva (recusa em responder ou em participar das atividades propostas, falta de engajamento ou mesmo desistência durante o ensino). Nesse sentido, técnicas de ensino sem erro podem ser úteis quando o ensino envolve crianças (Kato \& Maranhão, 2012; Melo et al., 2014).

Sendo assim, o presente estudo tem como objetivo descrever as etapas de estruturação e validação de um jogo didático sobre saúde bucal cujo propósito é promover o aprendizado sobre saúde bucal em escolares, estimular a prática da escovação dentária e fornecer orientações sobre alimentos cariogênicos e não cariogênicos.

\section{Metodologia}

Trata-se de um estudo metodológico (Polit \& Beck, 2018) que procurou descrever as etapas de estruturação de um jogo de tabuleiro sobre saúde bucal baseado no método CTM3 (Santos \& Warren, 2020) e na aprendizagem sem erros (Kato \& Maranhão, 2012; Melo, et al., 2014) e seu processo de validação.

O conteúdo e a condução do jogo adotaram procedimentos de ensino sem erros, que se referem, de maneira ampla, a um conjunto de procedimentos de ensino que resultam em desempenhos precisos ou com poucos erros, cujo processo conta com uma instrução prévia programada, cujo objetivo consiste em aumentar a probabilidade de acertos. A diminuição na ocorrência de erros é considerada como condição necessária para a aprendizagem e, o reforço de uma resposta no início de um processo de aprendizagem, aumenta a probabilidade de ocorrência de acertos. Esse tipo de aprendizagem é uma contribuição significativa para aquela que fracassa com métodos tradicionais e pode apresentar resultados em curto espaço de tempo, justificando-se, inclusive, para acelerar o ensino de habilidades mais complexas e fornecendo importantes elementos à mudança de práticas, em que o aplicador garante que a resposta do aluno esteja correta (Kato \& Maranhão, 2012; Melo et al., 2014).

Esse jogo passou por dois processos de validação: a) validação de conteúdo por especialistas e, b) validação por banca de defesa de um Programa de Mestrado Profissional de uma Instituição de Ensino Superior de Alagoas.

\subsection{Estrutura do jogo}

O jogo intitulado "Vamos aprender a ter uma boca saudável" foi desenvolvido para ser aplicado com crianças de 6 (seis) a 8 (oito) anos, que estão em ambiente escolar, visando proporcionar aos participantes, não apenas a aprendizagem sobre saúde bucal (escovação, alimentação saudável etc.), mas também despertar e estimular a prática da escovação dentária de forma divertida e informativa.

Trata-se de um jogo, tipo tabuleiro, em formato de boca, cujos dentes, em número de 32, dois sem numeração e os demais numerados de 1 a 30, apresentam possibilidades de conhecimento sobre os cuidados com a boca e de demonstração das técnicas de escovação e de uso do fio dental, conforme a idade das crianças participantes.

O jogo foi desenvolvido por uma designer gráfica, que seguiu o roteiro elaborado pelas autoras usando imagens de domínio público (https://www.freepik.com; https://pt.vecteezy.com). Com a arte e o processo de validação finalizados, o jogo foi impresso, digitalmente, em lona vinílica com tamanho aproximado de $9 \mathrm{~m}^{2}$. A versão final do jogo possui licença Creative Commons (Atribuição - Não Comercial - Compartilha Igual CC BY-NC-AS), que permite que outros remixem, adaptem e criem a partir do trabalho original para fins não comerciais, desde que atribuam aos autores o devido crédito e que licenciem as novas criações sob termos idênticos.

Esse produto foi adaptado do jogo Trilhando Saúde, que é um produto educacional desenvolvido por Novaes (2020), validado através de população alvo e juízes ad hoc e está disponível no Portal eduCAPES no endereço eletrônico https://educapes.capes.gov.br/handle/capes/568343. O Trilhando Saúde é um jogo de tabuleiro utilizado para educação 
permanente dos profissionais de saúde e aconselhamento dos usuários acerca da atividade física e que busca dar subsídios aos profissionais de saúde para realizarem o aconselhamento sobre atividade física, buscando o estímulo a prática de forma interativa e lúdica.

\subsection{Descrição das etapas do jogo}

O presente jogo seguiu as etapas do jogo original, Trilhando Saúde, fazendo adaptações para o tema saúde bucal e para a população em que será aplicado. Para tanto, o formato de trilha foi substituído por um formato de boca, as casas foram trocadas por dentes e os exercícios físicos deram lugar a atividades relacionadas à saúde bucal.

Para que o jogo fosse adequadamente apresentado, optou-se por, inicialmente, descrever os elementos que compõem a boca, depois apresentar as perguntas elaboradas e demonstrações orientadoras do jogo e, por fim, as atividades escolhidas para compor cada dente.

Vale ressaltar que há dentes voltados à flexibilização das atividades e adequação delas às necessidades de várias populações, realidades e contextos. Isso porque, há dentes em que a criança tira uma carta e outros em que ela realiza uma prenda e, nestes casos, a tarefa a ser realizada pela criança pode ser adaptada de acordo com as necessidades locais dos aplicadores e jogadores, dado que as cartas usadas podem ser mudadas e adequadas para quaisquer fins relativos à saúde bucal. O jogo contém, ainda, um cartão com a descrição do seu roteiro.

\subsubsection{Definição dos elementos que compõem a boca}

Na primeira etapa, "Definição dos elementos que compõe a boca", foram definidos os tipos de dentes, que fariam parte da boca. O jogo original (Trilhando Saúde) apresenta 7 tipos de casa: início, repouso, perguntas e respostas, exercícios físicos, avance, volte e chegada. Cada uma delas representa um elemento a ser informado, que geralmente se relaciona com os comandos a serem executados durante a partida.

Para o jogo proposto neste estudo, foram mantidas as casas início, perguntas e respostas, avance, volte e fim, já as casas exercício físico e repouso, foram substituídas por atividades para realizar e uma rodada sem jogar, respectivamente, e acrescidas as casas/dentes: a) demonstrações de escovação dos dentes, uso do fio dental e higienização da língua; b) textura, dentes em que a criança entra em contato com superfícies que simbolizam o dente bem escovado e o dente mal escovado; c) tire uma carta, dentes em que o professor irá apresentar informações sobre a cárie e o flúor, e, d) prenda, dente em que o aluno escolhe uma prenda para o adversário executar.

Então, no jogo "Vamos aprender a ter uma boca saudável", foram definidos 11 tipos de dentes, 4 a mais que no jogo original, com as devidas adaptações para a temática, são eles: início, demonstrações, perguntas e respostas, atividades para realizar, uma rodada sem jogar, tire uma carta, textura, avance, volte, prenda e fim.

Para que a aprendizagem ocorresse de forma prazerosa, procurou-se fazer orientações sobre saúde bucal antes de solicitar alguma atividade ao aluno, como por exemplo, realizar uma demonstração ou responder uma pergunta, uma vez que o objetivo do jogo é ensinar e não avaliar o conhecimento das crianças. Essa orientação atende a ideia de que o jogo não pode colocar a criança em situações de tentativa e erro, conforme mostra a literatura da área de psicologia (Kato \& Maranhão, 2012; Melo et al., 2014). Nesse sentido, a instrução do que é correto ocorre antes de se fazer uma pergunta, de solicitar alguma demonstração, ou de que qualquer outra atividade seja requisitada pelas crianças para sua execução.

A Tabela 1 sintetiza a disposição dos dentes por categoria, quantidade e localização no jogo. 
Tabela 1 - Elementos que compõe o jogo "Vamos aprender a ter uma boca saudável".

\begin{tabular}{l|c|c}
\hline \multicolumn{1}{c}{ ELEMENTO } & QUANTIDADE & NÚMERO DOS DENTES \\
\hline Início & 1 & Sem numeração \\
Demonstrações & 6 & $2,8,12,14,22,23$ \\
Perguntas e respostas & 2 & 3,11 \\
Atividades para realizar & 5 & $4,13,16,17,21$ \\
Uma rodada sem jogar & 2 & 5,30 \\
Tire uma carta & 5 & $1,7,10,25,28$ \\
Textura & 2 & 6,18 \\
Avançar & 4 & $8,15,22,23$ \\
Voltar & 5 & $9,20,26,27,29$ \\
Prenda & 2 & 19,24 \\
Fim & 1 & Sem numeração
\end{tabular}

Fonte: Autores (2021).

O dente "início" marca o ponto de partida do jogo e diz seu objetivo, assim como o dente "fim" marca o término do jogo, ambos sem numeração. O dente "uma rodada sem jogar" aparece duas vezes após a descrição de atitudes inadequadas a manutenção da saúde bucal.

Nos dentes "perguntas e respostas" ( 2 dentes), os participantes devem responder as perguntas referentes a hábitos saudáveis e de prevenção para saúde da boca, que estão no roteiro do jogo.

Nos dentes "atividades para realizar" (5 dentes), são passadas instruções do que é correto, já que não se pretende testar o conhecimento prévio da criança e é solicitado que realize determinada atividade (sobre hábitos saudáveis e higienização), procurando incorporar essas práticas, previstas no roteiro, aos hábitos diários da criança.

Em 5 (cinco) dentes, é apresentada uma informação sobre saúde bucal, e solicitado ao aluno que "tire uma carta", contendo uma tarefa, essas cartas têm o caráter de individualizar o jogo, tornando-o mais dinâmico, apresentando a oportunidade de modificações de acordo com a realidade identificada na população específica.

Os dentes "avance" (4 dentes) representam comportamentos considerados favoráveis à manutenção de uma boca saudável e, desse modo, recebem a vantagem de avançar certo número de dentes. Já os dentes "volte", representam comportamentos desfavoráveis e, por isso, recebem a desvantagem de voltar certo número de dentes. Antes de "avançar" ou "voltar", as crianças são esclarecidas sobre qual comportamento as leva a ter essa vantagem ou desvantagem. Todos os esclarecimentos constam no roteiro do jogo.

Nos dentes "demonstração" são passadas instruções de como realizar corretamente a escovação e usar o fio dental. Neles, é solicitado a criança que depois da instrução faça a demonstração de alguma etapa da higiene oral. São 6 dentes e em 3 deles, caso a criança realize corretamente a demonstração poderá avançar casas. Durante a demonstração é cantada a paródia "O Passeio".

Nos dentes "textura" (2 dentes), a criança entra em contato com a sensação de dente limpo e dente sujo, para que ela possa identificar na sua boca quando os dentes estão bem escovados ou quando precisa melhorar ou realizar a escovação.

Os dentes "prenda", aparecem duas vezes quando o comportamento for adequado a manutenção da saúde bucal, a equipe escolhe uma prenda para uma das outras equipes pagar e quando for desfavorável a equipe adversária escolhe a prenda. As prendas podem ser relativas aos problemas mais identificados na avaliação dos professores que utilizam o jogo. 


\subsubsection{Elaboração das perguntas, demonstrações e atividades para realizar}

Baseado na literatura da área de psicologia (Kato \& Maranhão, 2012; Melo et al., 2014), o jogo aqui descrito foi fundamentado em atividades que procuraram não expor as crianças constantemente ao erro. Por isso, as atividades dispostas no circuito do jogo contaram, em geral, com duas etapas de informações: 1) uma explicação do que seria o correto a ser feito para a ocorrência da saúde bucal e 2) uma atividade avaliativa, que poderia ser responder a perguntas, fazer demonstrações, escolher figuras etc. Dessa forma, garantiu-se o ensino com a primeira etapa e uma avaliação de aprendizagem com a segunda etapa.

As perguntas, demonstrações e atividades para realizar basearam-se nas recomendações do Ministério da Saúde (2006) e da Associação Brasileira de Odontopediatria (2020). As demonstrações, após orientação, podem ser facilmente reproduzidas. $\mathrm{O}$ roteiro do jogo indica o local e a orientação referente a cada um dos dentes.

\subsubsection{Em que teoria se baseou a feitura do jogo?}

O desenvolvimento desse jogo foi baseado no método CTM3 composto pela concepção do produto (C), referencial teórico (T) e referencial metodológico (M3). A concepção do produto é o momento inicial, em que se estabelece o tema, o tipo e quais elementos irão compor o produto; o referencial teórico é a busca realizada nas bases de dados para subsidiar as informações sobre a doença ou agravo que se deseja trabalhar e o referencial metodológico compreende as teorias que embasam a proposta para a feitura do produto: Análise Transacional, Aplicação Multissensorial e Neurolinguística (Santos \& Warren, 2020).

Baseou-se, também, nos procedimentos de ensino sem erros, cujo procedimento conta com uma instrução prévia programada, com o objetivo de aumentar a probabilidade de acertos. Essa técnica promove a aquisição de uma nova habilidade em curto espaço de tempo e com menos erros do que os métodos tradicionais, em que o aplicador garante que a resposta do aluno esteja correta (Kato \& Maranhão, 2012; Melo et al., 2014).

A análise transacional é uma teoria desenvolvida, em 1965, pelo psiquiatra americano, Eric Berne. Um dos elementos abordados nessa teoria é a estruturação de personalidade composta de três elementos, denominados Estados de Ego, são eles: Estado de Ego Pai, Adulto e Criança (Santos \& Warren, 2020). Os estados de ego representam a maneira como os indivíduos se comportam, dependendo dos pensamentos e emoções do momento, quando os indivíduos se comunicam e agem em função de uma dessas três estruturas, que é ativa neles, cada um com características diferentes e distintas em cada pessoa. Seria ideal que as pessoas tivessem disponibilidade dos três elementos sempre que fossem solicitadas nos momentos de interação (Santos et al., 2019).

O Estado de Ego Pai representa regras, normas, limites, cuidados, atenção e aprendizado adquiridos a partir de figuras parentais (pai, mãe, professores, tios, avós) e ensina ao indivíduo o certo, o errado e como deve agir e em quem acreditar (Santos et al., 2019; Santos \& Warren, 2020).

O Estado de Ego Adulto representa o pensamento lógico e abstrato, recebe informações externas e as avalia, analisa e toma decisões em virtude da racionalidade. Não há espaço para emoções, é pura racionalidade, em que a informação é analisada e processada de forma limpa e pensamento racional. É como se um computador tivesse implantado em cada indivíduo (Santos et al., 2019; Santos \& Warren, 2020).

O Estado de Ego Criança é responsável pelas emoções, alegria, prazer, amor, tristeza, medo e é também responsável pela fantasia, naturalidade, criatividade e espontaneidade. É o primeiro Estado de Ego a ser formado, nato do recém-nascido. É o espaço em que se concentram a criatividade e a arte (Santos et al., 2019; Santos \& Warren, 2020).

Uma das formas de comunicação do ser humano é a multissensorialidade, por meio dos canais que ele tem disponível, que são os cinco sentidos: visão, audição, olfato, paladar e tato (sensorial). É por intermédio dos sentidos que apreendemos as informações e sensações do mundo externo. Portanto, os cinco sentidos compõem uma importante ferramenta no processo de 
comunicação (Santos \& Warren, 2020). Para que se possa atingir o estado ou comportamento desejado para efetivar a mudança, é importante saber qual o acesso mais disponível no momento da atividade educativa, para tanto, deve-se conhecer dentre os sentidos (visão, paladar, olfato, gustação, tato), qual o mais disponível para cada pessoa ou comunidade (Santos \& Warren, 2020).

Uma das ferramentas da Programação Neurolinguística mais utilizadas no processo de elaboração de produtos educacionais corresponde às âncoras que, segundo O'Connor e Seymour (1995), são estímulos atuais que evocam uma experiência original, quando bem inseridas reforçam a todo momento o comportamento adequado (Santos et al., 2019; Santos e Warren, 2020). Essa é estabelecida quando após a atividade educativa é entregue a criança um adesivo perfumado (também evoca o sentido visual e olfativo) para que ela o cole em um local de fácil visualização por ele. Este contém as frases CUIDESE e LEMBRE-SE DE ESCOVAR OS DENTES que podem funcionar como mensagem subliminar, descrita por Santos e Warren (2020), como o elemento que não comunica diretamente, tendo a capacidade de vencer a resistência em captar a informação, agindo de forma inconsciente, aparecendo, também, uma cena da animação.

Santos, Warren, Trindade, Lima e Wyszomirska (2019) colocam que cada indivíduo é único, age e reage de uma forma peculiar a cada evento e que se deve saber quais canais estão disponíveis e como acessá-los (consciente ou inconscientemente). Destacam, ainda, que se deve usar toda "munição" para comunicar com todos os sentidos, garantindo, assim, que a comunicação se torne mais efetiva, tanto de forma verbal como não verbal, para que o processo de comunicação se transforme em aprendizado.

A Tabela 2 apresenta onde esses elementos são requeridos no jogo.

Tabela 2 - Distribuição do método CTM3 no jogo.

\begin{tabular}{|c|c|c|}
\hline TEORIA & FUNDAMENTO & ELEMENTOS INSERIDOS NO JOGO \\
\hline \multirow{3}{*}{$\begin{array}{c}\text { ANÁLISE } \\
\text { TRANSASIONAL }\end{array}$} & Ego Pai & $\begin{array}{l}\text { Cuidado em mostrar as crianças quais os comportamentos adequados e } \\
\text { inadequados à manutenção a saúde bucal (dentes avance e volte) }\end{array}$ \\
\hline & Ego Adulto & $\begin{array}{l}\text { Informações de como realizar a escovação de maneira correta (nos dentes } \\
\text { demonstração) }\end{array}$ \\
\hline & Ego Criança & Presente durante toda a execução do jogo, diversão \\
\hline \multirow{5}{*}{ MULTISENSORIALIDADE } & Visão & Formato do tabuleiro, colorido das imagens \\
\hline & Audição & Paródia cantada durante a demonstração de escovação (dentes $2,6,8,12$ e 22) \\
\hline & Olfato & Evocado pela sensação de hálito fresco ou mau hálito (dentes 26 e 28) \\
\hline & Paladar & Imagens de alimentos "bons e ruis" para os dentes (dentes 4 e 13) \\
\hline & Tato & Quando a criança entra em contato com a textura do tabuleiro (dentes 6 e 18) \\
\hline \multirow{2}{*}{ NEUROLINGÚISTICA } & Âncora & $\begin{array}{l}\text { Adesivo (perfumado) } \\
\text { Paródia }\end{array}$ \\
\hline & $\begin{array}{l}\text { Mensagem } \\
\text { subliminar }\end{array}$ & $\begin{array}{l}\text { CUIDE-SE } \\
\text { LEMBRE-SE DE ESCOVAR OS DENTES }\end{array}$ \\
\hline
\end{tabular}

Fonte: Autores (2021).

A aprendizagem sem erro é apresentada no jogo quando se obtém instruções pela explicação do professor, dando condições ao aluno de solucionar o problema ou executar a atividade proposta. Por exemplo, no dente 12, primeiro explica-se como deve ser realizada a escovação e depois solicita-se que ela seja feita, "Nos dentes de trás (na parte onde nós trituramos os alimentos) devemos passar a escova para frente e para trás, como se fosse um trenzinho. Mostre como você escova a parte do 
dente onde mastigamos os alimentos". Outro exemplo está no dente 4, em que a instrução é "Os alimentos bons para os dentes são frutas, verduras, leite e queijo. Encontre os alimentos saudáveis nas fotos dos dentes”. Então, sempre que for requerida alguma atividade, demonstração, pergunta, a informação do que é correto será passada antes.

\subsection{Validação do jogo}

A validação técnica é importante e se baseia na avaliação do produto educacional quanto à relação entre conteúdo e forma, para o alcance dos objetivos, considerando o público-alvo (Ruiz, Motta, Bruno, Demonte \& Tufró, 2014). A validação desse produto educacional seguiu as seguintes etapas: a) seleção dos especialistas (avaliadores), b) envio do material sobre a elaboração do produto, c) preenchimento dos instrumentos de avaliação e d) emissão de parecer de validação.

Houve uma etapa de validação de conteúdo, pode ser definida como a determinação da representatividade de itens que expressam um conteúdo baseada no julgamento de especialistas de uma área específica (D’avila, Puggina \& Fernandes, 2018). Foram avaliadas a conveniência e a facilidade de compreensão da linguagem utilizada assim como, se os conceitos mais importantes foram abordados com vocabulário claro e objetivo. Os pareceristas também indicaram possíveis erros conceituais. Em relação as ilustrações, os especialistas avaliaram a adequação da composição visual, sua atividade e organização, bem como a quantidade e a adequação (Jesus et al., 2020).

O jogo "Vamos aprender a ter uma boca saudável" foi avaliado com a colaboração de 3 (três) juízes especialistas ad hoc e por banca de defesa de Mestrado Profissional de uma Instituição de Ensino Superior de Alagoas. Os especialistas foram selecionados seguindo os critérios elencados por Leite (2018); Medeiros, Santos, Wanderley, Medeiros e Carvalho (2020); Jesus et al. (2020): a) possuir o título de doutor e/ou mestre nas áreas de educação, saúde ou comunicação, b) ter experiência profissional em atividades de promoção de saúde (clínica, ensino ou pesquisa) e/ou ter experiência relacionada a produção de materiais educativos e didáticos.

O convite aos especialistas foi viabilizado por meio de carta convite enviada por e-mail. Os três avaliadores convidados aceitaram participar da validação do jogo e assinaram o Termo de Consentimento Livre e Esclarecido (TCLE), especialmente elaborado para essa finalidade, e receberam, por meio eletrônico, e-mail, as informações sobre a elaboração do jogo, assim como os formulários para a sua avaliação. Tiveram um prazo de 15 dias para devolutiva dos formulários e emissão do parecer.

Os instrumentos para a coleta de informações foram dois formulários para avaliação do jogo. O primeiro formulário foi desenvolvido pelas autoras e nele os especialistas avaliaram as informações e instruções contidas nos dentes (casas do jogo), em seguida verificaram se as informações estavam de acordo com o objetivo proposto em cada dente e, nas que julgaram incompletas ou inadequadas, fizeram sugestões de adequações na maneira de apresentação das informações para atender à perspectiva dos jogadores.

O segundo formulário foi adaptado do instrumento de validação de conteúdo educativo em saúde elaborado e validado por Leite (2018), que teve o objetivo específico de avaliar conteúdos escritos de materiais educativos, excluindo-se figuras, imagens e desenhos. Esse instrumento apresenta três domínios: objetivos, estrutura e apresentação, e relevância. O objetivo deve englobar propósitos, metas ou finalidade da utilização do material educativo; a estrutura e a apresentação devem ter informações referentes a organização geral, estrutura, estratégia, coerência e suficiência das apresentações e, por fim, na relevância, deve-se avaliar a significação do conteúdo educativo apresentado e sua capacidade de causar impacto, motivação e/ou interesse.

O processo avaliativo considerou, ainda, clareza, pertinência prática, relevância teórica e dimensão na redação de cada item, observando os seguintes critérios: a) relevância social do tema, b) criatividade, c) qualidade visual, d) linguagem fácil e 
acessível, e) aplicabilidade, f) objetivos educacionais claros, g) adequação ao público-alvo, h) potencial de aprendizagem, e i) se o conteúdo e forma despertam interesse (Medeiros et al., 2020).

As respostas foram dadas em uma escala tipo Likert $(0$ - discordo, 1 - concordo parcialmente, 2 - concordo totalmente) (Leite, 2018). E, ao final, os especialistas emitiram um parecer quanto a validação do jogo, que poderia ser: validado, validado após correções ou não validado.

A banca de defesa fez a avaliação do jogo após os ajustes e as adequações que foram sugeridas pelos especialistas.

\section{Resultados e Discussão}

Após a avaliação do material enviado, o avaliador 1 emitiu o parecer validado e os avaliadores 2 e 3 emitiram o parecer validado após correções. Os dentes marcados com recomendações pelos pareceristas foram os dentes 2, 3, 6, 8, 9, 12, 16,18, 19, 22 e fim. As mudanças sugeridas, para melhoria do jogo, indicavam modificações na instrução de deveria ser passada pelo facilitador ao aluno para atingir os objetivos propostos, especificar melhor os comportamentos que as crianças devem emitir e tornar mais evidentes os objetivos de cada dente no jogo por meio da representação visual, para isso foram sugeridas alterações nas imagens dos dentes 2, 3, 16, 22 e fim.

As alterações sugeridas pelos avaliadores 2 e 3 foram realizadas e as adequações podem ser encontradas na Tabela 3 .

Tabela 3 - Ajustes sugeridos pelos avaliadores no roteiro do jogo.

\begin{tabular}{clc}
\hline DENTE & \multicolumn{1}{c}{ AJUSTE } & AVALIADOR \\
\hline 2 & Modificar o texto de instrução & 2 \\
& Adequar o objetivo & 3 \\
& Adequar a imagem & 3 \\
3 & Adequar a imagem & 3 \\
6 & Modificar o texto de instrução & 2 \\
& Explicar melhor o comportamento que a criança deve emitir & 3 \\
8 & Sugeriu intercalar a paródia usada no jogo com outras músicas & 2 \\
9 & Modificar o texto de instrução & 3 \\
12 & Mudar a grafia de um dos termos usados na instrução & 2 \\
16 & Modificar a imagem & 3 \\
18 & Explicar melhor o comportamento que a criança deve emitir & 3 \\
& Reescrever o objetivo & 3 \\
19 & Explicar melhor o comportamento que a criança deve emitir & 3 \\
& Melhorar o objetivo & 3 \\
FIM & Modificar a imagem & 3 \\
\hline
\end{tabular}

Fonte: Autores (2021).

Assim, os ajustes sugeridos pelos avaliadores foram realizados. A banca de defesa avaliou o jogo após os ajustes sugeridos pelos especialistas e emitiu o parecer validado sem alterações e a versão final do jogo pode ser obtida no Portal eduCAPES no endereço eletrônico https://educapes.capes.gov.br/handle/capes/642484.

\section{Considerações Finais}

O jogo "Vamos aprender a ter uma boca saudável" foi estruturado e validado para ajudar os professores a trabalharem a temática saúde bucal no ambiente escolar. Por se tratar de um processo divertido e atrativo espera-se despertar nas crianças que farão uso do jogo a vontade de realizar sua higiene oral e, nos professores o interesse em introduzir a temática saúde bucal em suas atividades didáticas.

Esta proposta de jogo didático traz instrumentos que buscam facilitar o processo ensino-aprendizagem, através do estabelecimento de práticas educativas preventivas e ludicidade, contribuindo para aumentar a autonomia das crianças no seu 
cuidado. Constituindo-se num veículo onde o processo de comunicação se transforme em aprendizado, levando a mudança de comportamento. Os métodos de aprendizagem consideraram a idade do público-alvo e o modelo de abordagem incidiu no papel de riscos modificáveis.

Desse modo, espera-se que esse jogo possa ser difundido na comunidade escolar, podendo contribuir para estimular a escovação dentária em crianças, melhorando assim os índices de saúde bucal. Sugere-se outras pesquisas que utilizem instrumentos a fim de facilitar o processo de ensino e aprendizagem sobre saúde bucal. Para estudos futuros sugere-se a aplicação do jogo em diversos cenários e públicos, e, que ele possa ser adequado a realidade encontrada.

\section{Referências}

Adistia, R., Wafa, W., Riyanti, E., Riyanti, E., \& Setiawan, A. S. P. P. (2020). Effectiviness of educational vídeo in improving oral hygiene in preschool students. Padjadjaran Journal of Dentistry, 2(32), 108-112.

Aguiar, N. L., Barros, W. R. C., Silva, I. F., Jr., Sinimbú, C. M. B., Barreto, L. M., Pereira, F. M., \& Nascimento, L. S. (2018). Jogo SB: estratégia lúdica de educação em saúde bucal para adolescentes na Amazônia. Interdisciplinary Journal of Health Education, 3(1-2), 46-53.

Araújo, L. G., Margotti, E., Rocha, A. G. M., Martins, M. B., Rodrigues, G. M. M., \& Conceição, N. T. (2021). O uso do jogo de tabuleiro humano na prevenção de acidentes domésticos na infância: relato de experiência. Interfaces - Revista de Extensão da UFMG, 9(1), 199-222.

Associação Brasileira de Odontopediatria Nacional. (2020). Diretrizes para procedimentos clínicos em odontopediatria (3a ed). Editora Santos.

Brasil. (2006). Cadernos de Atenção Básica, n. 17 - Saúde Bucal. Brasília: Ministério da Saúde. https://bvsms.saude.gov.br/bvs/publicacoes/saude_bucal.pdf

Brito, L. F., Ramos, R. A., Castro, J. F. B., Araújo, J., Ramos, R. P., \& Leal, B. G. (2020). NutriKids: jogo sério para o desenvolvimento do conhecimento nutricional em crianças e adolescentes. Revista Latinoamericana de Tecnologia Educativa, 19(1), 93-106.

Campestrini, N. T. F., Cunha, B. M., Kublitski, P. M. O., Kinger, L., Calderelli, P. G., \& Gabardo, M. C. L. (2019). Atividades educativas em saúde bucal desenvolvidas por cirurgiões-dentistas com escolares: uma revisão sistematizada da literatura. Revista da ABENO, 19(4), 46-54.

Casseb, T. F., Nascimento, L. S., Matos, P. B. L., Lopes, A. L. N., Lucas, A. C. M., Pires, M. J. M., Vieira, A. S. T., Souza, R. N. L., Galvão, S. S. C., \& Santos, I. O. O. (2020). O jogo "remo da saúde bucal” como ferramenta para educação em saúde bucal. Revista Eletrônica Acervo Saúde, 50, 1-10.

Castro, A. R., Arruda, A. M. C., Siqueira, P. H. G. S., \& Kawakami, R. M. S. A. (2018). Educação em saúde sobre cuidados com a higiene infantil e alimentação saudável na creche. In: Castro et al. (Anais). $1^{a}$ Mostra Científica do Programa de Interação Comunitária do Curso de Medicina - MT: Várzea Grande: 2018. Anais...Várzea Grande: Centro Universitário UNIVAG, 1, p. 43-45.

Corrêa, A. L., Emmi, D. T., Pinheiro, H. H. C., Barroso, R. F. F., Araújo, I. C., \& Araújo, M. V. A. (2019). Atenção em saúde bucal na creche Sorena: relato de experiência de 17 anos promovendo saúde em pré-escolares. Revista Conexão UEPG, 15(2), 142-146.

Costa, M. M., Barbosa, A. D. L., Fernandes, J. M. F. A., Fonseca, F. R. A., \& Paredes, S. O. O. (2017). Conhecimento e práticas em saúde bucal nas escolas de ensino fundamental de um município de pequeno porte do sertão paraibano. Arquivos em Odontologia, 50(4), $193-202$.

Costa, F. B. C. (2020). Jogo educativo para promoção da saúde cardiovascular em crianças. (Tese de Doutorado). Universidade de Fortaleza, Ceará.

Cota, A. L. S., \& Costa, B. J. (2017). A. Atividades lúdicas como estratégia para a promoção da saúde bucal infantil. Revista Saúde e Pesquisa, 10(2), 365371.

D’avila, C. G., Puggina, A. C., \& Fernandes, R. A. Q. (2018). Construção e validação de um jogo educativo para gestantes. Escola Anna Nery, 22(3), 1-8.

Fadel, C. B., Machado, C. A., Fº, Mansani, G. C., Periera, M. V. S., \& Martins, A. S. (2018). Jogo para celular como instrumento de educação em saúde bucal. Rev. Ciênc. Ext., 14(2), 74-81.

Ferri, K. C. F., \& Soares, L. M. A. (2015). O jogo de tabuleiro como recurso didático no ensino médio: uma contextualização do ensino de química. In: Ferri, K. C. F., e Soares, L. M. A. (Anais). XII SEMANA DE LICENCIATURA - GO: Jataí: 2015. Anais... Jataí: Instituto Federal Goiás, p. $315-327$.

Figueiredo, M. C., Garcia, M., Barone, D. A. C., Oliveira, R., \& Lurmmerz, G. (2015). Gamificação em saúde bucal: experiência com escolares da zona rural. Revista da ABENO, 15(3), 98-108.

Garcia, P. P. N. S., Nogueira, I., Dorigo, L. N., Dotta, E. A. V., Dorigo, M. R. P. N., Nassouur, E. I. S. C., e \& Campos, J. A. D. B. (2009). Educação em saúde: efeito de um método de auto-instrução sobre os níveis de higiene oral em escolares. Pesq. Bras. Odontop. Clin. Integr., 9(3), 333-337.

Gonçalves, S., Cardozo, D. S., Pereira, R. F., \& Silveira, D. M. (2020). Promovendo hábitos de higiene na educação infantil: um relato de experiência da PIBID pedagogia. In: Gonçalves et al. (Anais).11 ${ }^{\circ}$ Salão Internacional de Ensino, Pesquisa e Extensão - UNIPAMPA: 2020. Salão de Extensão,11(3). Recuperado em 15 abril, 2020, de https://periodicos.unipampa.edu.br/index.php/SIEPE/article/view/107674

Jesus, G. J., Caliari, J. S., Oliveira, L. B., Queiroz, A. A. L. F. N., Figueiredo, R. M., \& Reis, R. K. (2020). Construção e validação de material educativo para promoção de saúde de pessoas com HIV. Revista Latino-Americana de Enfermagem, 28, 1-10. https://www.scielo.br/j/rlae/a/b584msKGkNrYLJyXBbhVWsh/?lang=pt. 
Kato, O. M., \& Maranhão, C. M. A. (2012). Procedimentos de ensino da leitura e aprendizagem sem erros. In: J. S. Carmo, e M. J. F. X. Ribeiro (org.). Contribuições da análise do comportamento à prática educacional (pp. 152-179). ESETec. Editores Associados.

Kishimoto, T. M. (1994). O jogo e a educação infantil. Pioneira.

Kishimoto, T. M. (1996). Jogo, brinquedo, brincadeiras e educação. Cortez.

Kishimoto, T. M. (2004). Froebel e a concepção do jogo infantil. Revista da Faculdade de Educação, 22(1), 145-168.

Leite, P. S. C. (2018). Produtos educacionais em mestrados profissionais na área de ensino: uma proposta de avaliação coletiva de materiais educativos. Investigação qualitativa em educação. Atas, CIAIQ 2018, 1, 330-339.

Lima, N. K. G., Araújo, M. M., Gomes, E. B., Vieira, N. R., Lima, F. J. R., Fo, Silva, J. C., Oliviera, C. J. \& Félix, N. D. C. (2020). Proposta de jogo como tecnologia educacional para a promoção de saúde cardiovascular do adolescente. Brazilian Journal of Health Review, 3(5), 13494-13514.

Mallmann, D. G., Galindo, N. M., Neto, Sousa, J. C., \& Vasconcelos, E. M. R. (2015). Educação em saúde como principal alternativa para promover a saúde do idoso. Ciência \& Saúde Coletiva, 20(6), 1763-1777.

Medeiros, I. C. F., Santos, A. A., Wanderley, F. A. C., Medeiros, F. M., \& Carvalho, A. M., F. (2020). Estruturação de um aplicativo como produto educacional em saúde. Revista Novas Tecnologias em Educação, 8(1).

Melo, R. M., Carmo, J. S., \& Hanna, E. S. (2014). Ensino sem erro e aprendizagem de discriminação. Temas em Psicologia, 22(1), 207-222.

Mouta, A. A. N., Silva, N. S., Souza, S. K. M., Silva, A. C. B., Costa, T. R. M., Silva, D. A., Souza, R. I. M. B., Oliveira, J. E. M., Lopes, S. D. S., \& Beltrão, R. P. L. (2020). Saúde na escola: utilização do lúdico na educação básica para conscientização sobre higiene pessoal e a prática da lavagem das mãos. Revista Eletrônica Acervo Saúde, 50, 1-8.

Novaes, C. R. M. N. (2020). Análise de formação, atualização e competências dos profissionais de Educação Física que atuam em prog ramas na Atenção Básica no estado de Alagoas. (Dissertação de Mestrado). Universidade de Ciências da Saúde de Alagoas, Maceió.

Oliveira, T. J. S., Santos, A. A., \& Santos, T. J. (2002). Aplicação de jogos educativos - uma avaliação de mudança no hábito de higienização bucal. Odontologia Clin. Cientif., 1(2), 123-128.

Oliveira, E. J. P., Barbosa, D. D., Ferreira, O. M., Jr., Fernandes, L. A., Pereira, A. A., \& Lima, D. C. (2016). 'Heróis da saúde bucal': saúde bucal numa abordagem lúdico recreativa. Revista de Ciências em Extensão, 12(3), 55-65.

Oliviera, M. M. D., Silva, N. M. S. \& Siqueira, A. C. (2018). O uso de um jogo de tabuleiro sobre saúde mental como estratégia para promoção de saúde. GEP NEWS, 2(2), 184-190

Polit, D. F. \& Beck, C. T. (2018). Fundamentos da pesquisa em enfermagem: avaliação de evidências para a prática de enfermagem. Artmed.

Prado, L. T. (2018). Jogos de tabuleiro modernos como ferramentas pedagógicas: panoramic e o ensino de ciências. Revista Eletrônica Ludus Scientiae, 2(2), 26-38.

Ruiz, L., Motta, L., Bruno, D., Demonte, F., \& Tufró, 1. (2014). Producción de materiales de comunicación y educacación popular. Cuidad Autônoma de Buenos Aires: Departamento de Publicaciones de la Facultad de Derecho y Ciencias Sociales de la Universidad de Buenos Aires.

Santos, A. A., Alves, C. F., Warren, E. M. C., \& Wyszomirska, R. M. A. F. (2019). Integrated Model of Course Based on Edu-Communication and PsychoCommunication in Learning. Creative Education, 10(6),1080-1090. https://file.scirp.org/pdf/CE_2019061115430264.pdf.

Santos, A. A., Warren, E. M. C., Trindade, E. M., Fo, Lima, M. A., \& Wyszomirska, R. M. F. A (2019). Produtos Educacionais na Educação em Saúde. In: A. L. B. A. Marques, D. J. Francisco, R. M. B. Melo, e S. Natividade, S. (org.). Interfaces entre educação e saúde: trilhando caminhos (pp. 45-53). CRV.

Santos, A. A., \& Warren, E. M. C. (2020). Método CTM3 como dispositivo de ensino, aprendizagem e comunicação em produtos educacionais. In: A. A. Santos (org.), Educação em saúde: trabalhando com produtos educacionais (pp. 13-30). Maceió: Hawking.

Santos, A. A., Warren, E. M. C., Guimarães, J. A. T. L., \& Lima, M. A. (2020). Cárie Dentária. In: A. A. Santos (org.), Educação em saúde: trabalhando com produtos educacionais (pp. 44-57). Maceió: Hawking.

Venâncio, D. R., Gibilini, C., Batista, M. J., Gonçalo, C. S., \& Sousa, M. L. R. (2011). Promoção da saúde bucal: desenvolvendo material lúdico para crianças na faixa etária pré-escolar. Revista do Instituto de Ciências da Saúde, 29(3), 153-156. 